
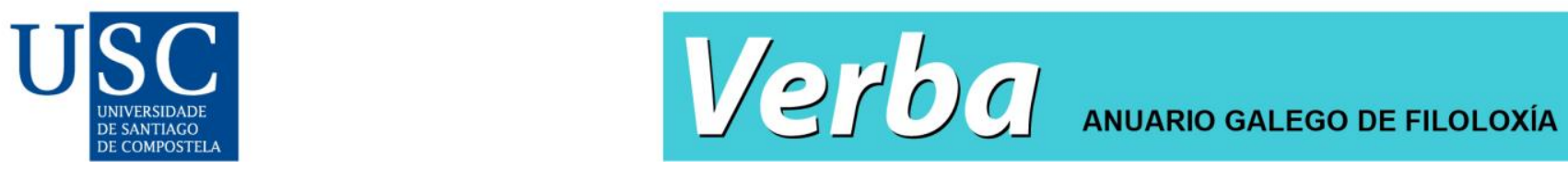

Verba: Anuario Galego de Filoloxía, 48, 2021. ISSN: 2174-4017

https://doi.org/10.15304/verba.48.6960

Revista de libros

\title{
Susana Rodríguez Rosique (2019): El futuro en español. Tiempo, conocimiento, interacción. Berna: Peter Lang. 259 páginas
}

\author{
Julio Torres Soler ${ }^{1}$ \\ ${ }^{1}$ Universidad de Alicante, España
}

Este libro de la profesora Susana Rodríguez Rosique aborda la problemática que entraña el estatus categorial del futuro sintético en español. Para ello, se estudian los diversos valores del futuro, cuya interpretación había sido sustancialmente diferente, según los lingüistas hubieran dado prioridad al componente temporal, modal o evidencial. Además, se analizan con especial atención los usos discusivos del futuro, en particular el futuro persuasivo, el futuro concesivo y el futuro mirativo, que hasta el momento no habían recibido la atención necesaria en el debate sobre la cuestión categorial. El resultado es una reformulación del futuro sintético basada en la instrucción deíctica de distancia hacia delante, que permite dar cuenta de todos los sus valores de forma unitaria.

El libro está formado por siete capítulos y un prólogo, en el que se presenta el volumen. En el primer capítulo, se revisa la explicación que se ha hecho del futuro sintético desde la gramática tradicional. Como desinencia verbal, se ha considerado una marca esencialmente temporal y aspectualmente neutra. Desde el punto de vista deíctico, el futuro se ha definido por la expresión de la posterioridad respecto al momento de enunciación. Además, junto con su valor temporal, el futuro puede desarrollar distintos valores modales en función del contexto, que vienen dados por su naturaleza deíctica, como la predicción, la obligación, la promesa y la verdad universal. Sin embargo, según la autora, el mayor problema que presenta la definición tradicional del futuro tiene que ver con un valor modal que no expresa posterioridad sino simultaneidad, indicando en ese caso que un evento es probable. Esto ha llevado a muchos autores en las últimas décadas a proponer visiones alternativas del futuro.

En el segundo capítulo, se explora la dimensión modal del futuro. En concreto, se describe el valor modal del futuro cuando este indica simultaneidad, que es considerado por varios autores un uso derivado o dislocado del tiempo verbal. A continuación, el valor del futuro que antes se había descrito como modal se revisa ahora desde el punto de vista de la evidencialidad, ya que se trata de una información que resulta de una inferencia o de un proceso de razonamiento. Además, cuando se ofrece información basada en inferencias, puede haber distinto grado de compromiso del hablante respecto a la proposición. Para averiguar el grado de compromiso del hablante 
respecto a los enunciados con futuro epistémico en español, la autora lleva a cabo un análisis de corpus del patrón "adverbio modal + futuro del verbo ser". El análisis revela que las combinaciones preferentes son probablemente + futuro y seguramente + futuro. También se analizan casos del futuro combinado con el adverbio necesariamente. A partir de estos datos, la autora concluye que el terreno natural del futuro epistémico es la probabilidad, aunque también puede aparecer con adverbios de posibilidad, en menor medida.

En la segunda parte del capítulo, se revisan varias interpretaciones diferentes que en las últimas décadas se han hecho del futuro. En primer lugar, se aborda la concepción del futuro como categoría modal, que ha sido desarrollada por Bertinetto (1979) y más recientemente por Giannakidou y Mari $(2012,2013)$. Desde esta óptica, el futuro se considera un operador modal de necesidad epistémica, mientras que el valor temporal del futuro sería tan solo una lectura derivada de su valor modal. En segundo lugar, se abordan algunas nuevas explicaciones futuro que parten de su valor temporal y que abarcan su valor epistémico, que se considera como una consecuencia de la restricción del dominio (Kissine, 2008) o como el resultado de un enriquecimiento pragmático (De Saussure, 2013). En tercer lugar, la autora se detiene particularmente a revisar la concepción del futuro de Escandell Vidal $(2010,2014)$, quien considera que el futuro es un evidencial gramatical, mientras que los usos temporales y epistémicos serían desarrollos pragmáticos del significado evidencial. Para la autora, la concepción estricta del futuro como evidencial, defendida por Escandell Vidal, no permite dar cuenta de los distintos valores del futuro, en particular de valores discursivos. Por último, se revisa la concepción del futuro que propone la Gramática Cognitiva, particularmente en los trabajos de Langacker $(1991,2011)$ y de Brisard (1997). En el enfoque cognitivista, el debate entre temporalidad y modalidad queda diluido, porque ambas categorías se analizan de forma más amplia como mecanismos de anclaje, entendiendo el anclaje como un proceso de contextualización. Al debate suscitado por las diferentes concepciones del futuro revisadas, se suma la necesidad de dar cuenta de los valores discursivos del futuro, poco explorados hasta el momento.

En el tercer capítulo, la autora propone una reformulación del futuro basada en la instrucción deíctica de distancia hacia delante. Para ello, en primer lugar, se presentan algunos hallazgos sobre la espacialización del tiempo, como la propuesta de Lakoff y Johnson (1999), quienes consideran que el tiempo es un concepto altamente metafórico, basado en nuestra concepción del movimiento en el espacio. Para la autora, la configuración espacial del tiempo permite definir el futuro a partir de la instrucción deíctica de distancia hacia delante, que puede proyectarse en diferentes niveles de un eje de subjetividad, expresando distintos significados. El eje de subjetividad se articula en tres niveles, el nivel del contenido, el nivel epistémico y el nivel de enunciación, que conllevan progresivamente una mayor inclusión de la perspectiva del hablante en el enunciado. En el nivel del contenido, la distancia hacia delante se proyecta sobre el contenido de la proposición y se interpreta en términos de posterioridad temporal, por lo que el futuro actúa como una categoría temporal, aunque además pueda asociarse con diversos valores modales. En el nivel epistémico, la instrucción de distancia hacia delante actúa sobre la proposición en sí misma y puede ser interpretada en términos modales o evidenciales. Desde el punto de vista evidencial, la distancia hacia delante se justifica porque una deducción siempre es posterior a su evidencia, mientras que, desde el punto de vista modal, la distancia hacia delante se explica porque el evento está sujeto a una corroboración posterior. Por último, en el nivel de enunciación, la distancia hacia delante se proyecta sobre el acto de habla y desarrolla diversas funciones con un alto grado de intersubjetividad. 
En el cuarto capítulo se aborda la relación entre gramática y estructura informativa. En primer lugar, se explica que la comunicación es un tipo de actividad conjunta, siendo la conversación cara a cara su forma más básica. Para que la comunicación se produzca, es necesario que exista un conocimiento compartido por los hablantes, que procede de la cultura. Además, desde el punto de vista de la ciencia cognitiva, se asume que la conciencia humana es de naturaleza focal, por lo que solo puede activar una pequeña parte de su conocimiento del mundo en cada momento, concretamente aquella que es relevante para la comunicación. Teniendo en cuenta los conceptos de conocimiento compartido y de activación cognitiva, se revisan varias propuestas de clasificación de la información nueva y conocida en la estructura informativa. Por lo que respecta al futuro, la autora afirma que, cuando lo expresado en futuro es una información previamente activada, entonces la instrucción de distancia hacia delante se proyecta sobre la enunciación y el futuro desempeña una función discursiva.

En el quinto capítulo se analizan los usos discursivos del futuro. En primer lugar, se revisan algunas propuestas recientes en las que se sistematiza el conocimiento compartido por los hablantes, debido a la importancia que este tiene en los usos discursivos del futuro. Por un lado, se revisa la propuesta de Bermúdez (2005), en cuyo análisis de la evidencialidad introduce un nuevo eje entre el acceso privativo y universal a la información. Por otro lado, se revisa la propuesta de Nuyts $(2001,2012)$, que defiende que la información puede ser subjetiva, cuando solo el hablante tiene acceso a la evidencia y, por tanto, se hace responsable de ella, o bien intersubjetiva, cuando la evidencia se presenta como conocida por un grupo amplio de personas, en cuyo caso la responsabilidad sería compartida. A continuación, se analiza el primero de los usos discursivos del futuro, el futuro persuasivo (p. ej. comprenderás que ya no pude dejar ya el periodismo), que aparece con un grupo restringido de verbos que indican una actividad mental o expresan acuerdo, como comprender, reconocer o entender. El futuro persuasivo presenta una información como inferible o accesible para el destinatario en el momento de la enunciación, concretamente como el resultado de un argumento previo, de manera que el enunciado adquiere un valor argumentativo persuasivo en el discurso. La instrucción de distancia se actualiza en el nivel del enunciado, puesto que la información expresada en futuro se presenta como una deducción posterior al discurso previo del hablante.

En segundo lugar, se aborda el futuro concesivo (p. ej. Pedro será muy inteligente, pero no lo demuestra), que según la autora, desempeña una función contraargumentativa. Tras revisar las propuestas de otros autores sobre este uso discursivo del futuro, se defiende que el futuro concesivo se da en entornos contraargumentativos, siempre que la información expresada en futuro constituye el foco de activación en el momento de enunciación. En estos casos, la instrucción deíctica de distancia hacia delante provoca un efecto desrealizante sobre la información expresada en futuro, lo que contribuye a reforzar la idea posterior, normalmente introducida por pero. En tercer lugar, se analiza el futuro mirativo (p. ej. ¡será idiota el tonto que tengo por marido!). Para ello, primero se define la miratividad y se discute su estatus categorial. A continuación, se defiende que el futuro mirativo desempeña una función evaluativa cuando la información expresada en futuro es accesible en el momento de la enunciación. En concreto, la instrucción deíctica de distancia hacia delante se proyecta sobre el acto de habla, de forma que el futuro realiza evaluación distanciada de una situación que está previamente activada en el contexto.

En el sexto capítulo, se analiza la estructura será posible que, a diferencia de los usos del futuro anteriormente analizados, experimenta un proceso de fijación particular. A partir de los datos que 
ofrece el CORDE, se estudian los cambios que experimenta será posible desde su valor como estructura composicional hasta su significado evaluativo, cercano al futuro mirativo anteriormente analizado. La autora concluye que será posible experimenta un proceso de gramaticalización (o pragmaticalización) por el cual el significado del futuro se desplaza desde el valor temporal hasta valor evaluativo, concretamente a partir de entornos interrogativos, mientras que se produce una fijación a nivel formal y una restricción de registro.

En el séptimo capítulo se recapitula la propuesta de reformulación del futuro presente en el volumen y se pone en relación con algunos mecanismos generales de cambio lingüístico. Por un lado, los valores discursivos del futuro se contemplan desde la perspectiva de la Gramática de Construcciones, desde la cual podrían considerarse casos de construccionalización, ya que exhiben un cambio de significado acompañado de restricciones formales. Por otro lado, desde la perspectiva de la Gramática del Discurso, la estructura será posible, así como el futuro mirativo, formarían parte de la gramática tética, ya que desempeñan funciones metacomunicativas, mientras que el futuro concesivo y el futuro persuasivo se encontrarían en el límite de lo que se considera gramática tética y gramática oracional. La autora concluye que, independientemente de la perspectiva adoptada, se ha demostrado que el futuro en español sigue transformándose en el camino de la gramaticalización.

En definitiva, este volumen monográfico de Susana Rodríguez Rosique supone una importante contribución al conocimiento de los diversos valores del futuro sintético en español, en especial de los usos discursivos. La reformulación del futuro que plantea la autora contribuye a desencallar el debate sobre el estatus categorial del futuro, abogando por una lectura unitaria que atiende a la diversidad de su polisemia. Además, la propuesta de la autora se apoya en varios desarrollos teóricos de gran interés en la actualidad, como la estructura informativa, el conocimiento compartido o la (inter)subjetivación, lo que demuestra la naturaleza multidimensional de la gramática. Por tanto, este libro es una lectura imprescindible para quienes estén interesados en conocer los valores del futuro sintético en español, pero también presenta un indudable interés para todos aquellos que deseen una lectura actualizada que ponga el foco en las relaciones entre la gramática y otras dimensiones del lenguaje.

\section{Bibliografía}

Bermúdez, F. W. (2005): La evidencialidad. La codificación pragmática del punto de vista (Tesis doctoral). Stockholms Universitet.

Bertinetto, P. M. (1979): “Alcune ipotesi sul nostro futuro (con osservazioni su potere e dovere)”, Rivista di Grammatica Generativa 4(1-2), pp. 77-138.

Brisard, F. (1997): "The English-tense system as an epistemic category: The case of futurity", en M. Verspoor (ed.), Lexical and syntactical constructions and the construction of meaning. Amsterdam / Philadelphia: John Benjamins, pp. 271-285.

Escandell Vidal, M. V. (2010): “Futuro y evidencialidad”, Anuario de Lingüística Hispánica 26, pp. 9-34.

Escandell Vidal, M. V. (2014): “Evidential futures: The case of Spanish”, en P. De Brabanter, M. Kissine y S. Sharifzadeh (eds.), Future times, future tenses. Oxford: Oxford University Press, pp. 219-246. 
Giannakidou, A. y A. Mari (2012): “The future of Greek and Italian: An epistemic analysis”, Proceedings of $\begin{array}{llll}\text { Sinn } & \text { und } \quad \text { Bedeutung 255-270. }\end{array}$ <http:semanticsarchive.net/Archive/Dk3NGEwY/GiannakidouMari.pdf>.

Giannakidou, A. y A. Mari (2013): "The weakness of future morphemes and epistemic modals: modal adverbs measuring speaker's confidence". <http://home.uchicago.edu/ giannaki/pubs/PaperCUP.5.6.pdf>.

Kissine, M. (2008): “Why will is not a modal?”, Natural Language Semantics 16(2), pp. 129-155.

Lakoff, G. y M. Johnson (1999): Philosophy in the flesh. The embodied mind and its challenge to western world. New York: Basic Books.

Langacker, R. (1991): Foundations of Cognitive Grammar. Vol 2. Stanford: Satnford University Press.

Langacker, R. (2011): “The English present: Temporal coincidence vs. epistemic immediacy”, en A. Patard y F. Brisard (eds.), Cognitive approaches to tense, aspect and epistemic modality. Amsterdam / Philadelphia: John Benjamins, pp. 45-86.

Nuyts, J. (2001): Epistemic modality, language and conceptualization. Amsterdam / Philadelphia: John Benjamins.

Nuyts, J. (2012): “Notions of (inter)subjectivity”, English Text Constructions 5(1), pp. 53-76. 